\title{
IS VERTICAL SHEAR IN AN ICE SHELF NEGLIGIBLE?
}

\author{
By T. J. O. Sanderson and C. S. M. Doake \\ (British Antarctic Survey, Natural Environment Research Council, Madingley Road, \\ Cambridge $\mathrm{CB}_{3}$ oET, England)
}

\begin{abstract}
Vertical shear stress in ice shelves cannot be precisely zero, since the upper and lower surfaces are generally not parallel. By performing stress balance on a vertical column in an ice shelf we calculate what its magnitude must be. This is done for an unconfined glacier tongue and for a confined bay ice shelf; first, using the assumption of constant temperature and density with depth, and secondly, using realistic data and profiles for Erebus Glacier tongue and for the Amery Ice Shelf. Shear stresses increase almost linearly with depth and are proportional to surface slope. For Erebus Glacier tongue the shear stress is at most $5 \%$ of the magnitude of the direct stress deviators and its action through the ice shelf should result in differential movement of $1.8 \mathrm{~cm} \mathrm{a}^{-1}$ between the top and bottom of the ice shelf. For the Amery Ice Shelf, the shear stress is at most $0.4 \%$ of the magnitude of the direct stress deviators and this should lead to differential movement of $2.5 \mathrm{~cm} \mathrm{a} \mathrm{a}^{-1}$ between the top and bottom of the ice shelf. Shear stresses are therefore generally negligible in comparison with direct stress deviators and can be ignored when considering the overall dynamics of ice shelves. Differential movement is unlikely to be detectable.
\end{abstract}

RÉsumÉ. Le cisaillement vertical dans une platforme de glace est-il négligeable? La tension de cisaillement dans les platformes de glace ne peut être rigoureusement nul, puisque les surfaces supérieures et inférieures ne sont généralement pas parallèles. En établissant le bilan des contraintes sur une colonne verticale dans une platforme de glace nous calculons ce que peut $x$ tre leur ordre de grandeur. Ceci est fait pour une langue flottante de glacier et pour une platforme dans une baie, d'abord dans l'hypothèse d'une densité et d'une température constante, quelle que soit la profondeur, ensuite en utilisant les résultats de profils réels exécutés sur la langue flottante de l'Erebus Glacier et sur l'A mery Ice Shelf. Les tensions de cisaillements augmentent presque linéairement avec la profondeur et sont proportionnels à la pente de la surface. Pour la langue flottante de l'Erebus Glacier, le cisaillement est au plus de $5 \%$ de l'ordre de grandeur des déviateurs directs des contraintes, et son action à travers la calotte produit un mouvement différentiel de $1,8 \mathrm{~cm} \mathrm{a}^{-1}$ entre le sommet et le fond du glacier. Pour l'Amery Ice Shelf, le cisaillement est au plus de $0,4 \%$ de l'ordre de grandeur des déviateurs directs des contraintes et ceci conduit à un mouvement différentiel de $2,5 \mathrm{~cm} \mathrm{a}^{-1}$ entre le haut et le fond de la platforme. Les cisaillements sont donc généralement négligeables devant les contraintes directes et peuvent être ignorés quant on considère la dynamique globale des platformes. Il est peu probable que les mouvements différentiels puissent être décelables.

Zusammenfassung. Ist Vertikalscherung in einem Schelfeis vernachlässigbar? Die vertikale Scherspannung in Schelfeisen kann nicht genau Null sein, da die obere Begrenzungsfläche im allgemeinen nicht parallel zur unteren ist. Aus dem Ansatz eines Spannungsgleichgewichtes in einer vertikalen Säule durch das Schelfeis ergibt sich die Grösse der vertikalen Scherspannung. Der Ansatz erstreckt sich auf eine unbegrenzte Gletscherzunge und auf ein begrenztes Bucht-Schelfeis, wobei zunächst die Annahme konstanter Temperatur und Dichte mit der Tiefe getroffen wird und dann echtes Datenmaterial und Profile für die Zunge des ErebusGlaciers und für das Amery-lce Shelf herangezogen werden. Die Scherspannungen wachsen nahezu linear mit der Tiefe an und sind proportional zur Oberflächenneigung. Für die Erebus-Zunge beträgt die Scherspannung höchstens $5 \%$ des Wertes der unmittelbaren Spannungsdeviatoren; ihre Wirkung durch das Schelfeis sollte zu einer differentiellen Bewegung von $\mathrm{I}, 8 \mathrm{~cm} \mathrm{a} \mathrm{a}^{-1}$ zwischen Oberfläche und Unterseite des Schelfeises führen. Für das Amery-Ice Shelf betragen die entsprechenden Werte höchstens $0,4 \%$ und $2,5 \mathrm{~cm} \mathrm{a}^{-1}$. Scherspannungen sind daher im allgemeinen gegenüber den unmittelbaren Spannungsdeviatoren zu vernachlässigen und brauchen bei der Untersuchung der Gesamtdynamik von Schelfeisen nicht berücksichtigt zu werden. Die differentielle Bewegung dürfte kaum feststellbar sein.

\section{INTRODUCTION}

It is usually assumed in discussing the dynamics of ice shelves that vertical shear quantities are negligible (Weertman, I957; Budd, I966; Thomas, 1973[b]; Robin, I975; Sanderson, in press); in Thomas (1973[b]) it is the sole restriction. It is worthwhile proving that this assumption is justified.

Early literature on ice shelves considered them to be of uniform thickness (Robin, I953; Weertman, 1957). In this case it is true that vertical shear is zero, since the ice shelf is a uniform horizontal slab subject to zero friction at its upper and lower surfaces. It is, however, now clear that most ice shelves have appreciable thickness gradients, and in this case shear stresses are no longer precisely zero. This can be illustrated by considering ice as a perfectly plastic material and looking at the slip-line field through an ice shelf (Fig. I). A slip-line field is represented by two orthogonal families of curves drawn so that their directions at any point coincide with the two perpendicular directions of maximum shear stress. Since the 
upper and lower surfaces of the ice shelf are subject to zero friction this means that slip lines must meet them at $45^{\circ}$. For the case of a uniform-slab ice shelf, the slip-line field is simple: lines pass straight through the ice shelf at $45^{\circ}$ to the horizontal (Fig. Ia). For the case of a slab with varying thickness, however, the slip lines must curve in order to meet both surfaces at $45^{\circ}$ (Fig. Ib). This curvature of the slip lines is associated with a varying component of shear stress in the vertical direction. We shall develop a method for calculating its magnitude by using a realistic power flow law for the flow properties of ice. The method involves the assumption that velocity is uniform through an ice shelf and the demonstration that this assumption is not perfectly self-consistent: it requires the existence of small shear stresses and hence small shear strain-rates.

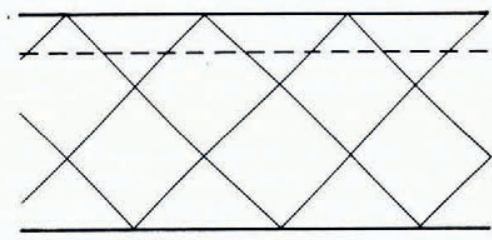

a

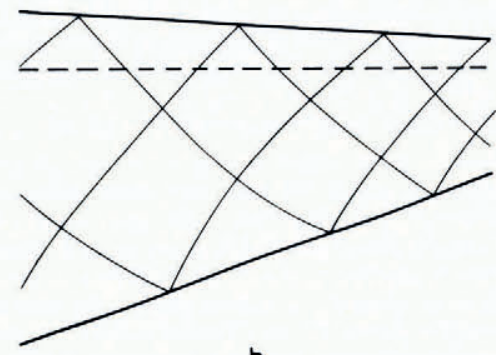

b

Fig. I. Schematic diagram of slip-line field through an ice shelf modelled as a plastic material: a. horizontal, parallel-sided ice shelf; b. ice shelf with thickness gradient. The dashed line represents sea-level.

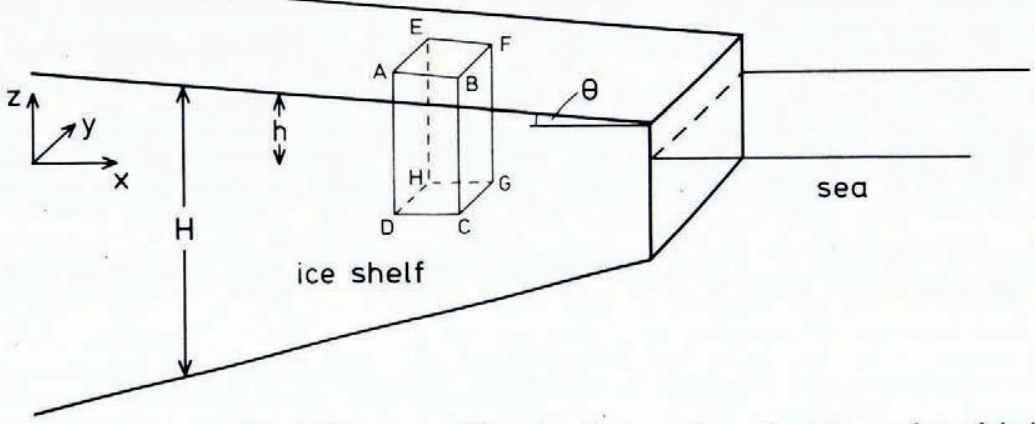

Fig. 2. Symbols used in discussion of ice-shelf stresses. The rectangle ABFE lies on the upper surface of the ice shelf and the rectangle cDHG is horizontal at some depth in the body of the ice shelf.

\section{i. Shear stresses}

\section{Unconfined ice shelves}

We define axes as in Figure 2. The $x$-axis is horizontal in the direction of flow and the $z$ axis is measured vertically upwards from sea-level. The ice thickness is $H$ and the elevation of the upper surface is $h$. The surface slope is $\theta$. The density of the ice is $\rho$ which we, for the moment, assume to be constant with depth. Direct stresses are denoted by $\sigma_{x x}, \sigma_{y y}$, and $\sigma_{z z}$, and shear stresses are denoted by $\sigma_{x y}, \sigma_{x z}$, and $\sigma_{y z}$. We assume the flow-law form (Paterson, i 969 , chapter 6)

$$
\dot{\epsilon}_{i j}=B^{-n} \tau^{n-1} \sigma_{i j} \quad(i, j=x, y, z),
$$

where $\dot{\epsilon}_{i j}$ is the strain-rate. Stress deviators $\sigma_{y}{ }^{\prime}$ are defined through

$$
\sigma_{i j}{ }^{\prime}=\sigma_{i j}-\delta_{i j} p \text {, }
$$


where $p$ is hydrostatic pressure, and $\delta_{i j}=\mathrm{I}$ if $i=j$, and $\delta_{i j}=0$ if $i \neq j$. The effective stress $\tau$ is defined by

$$
2 \tau^{2}=\sigma_{i j}{ }^{\prime} \sigma_{i j}{ }^{\prime} .
$$

$B$ is an empirical constant which is temperature dependent; we begin by assuming it to be constant through the ice shelf. We take $n=3$.

For quasi-static creep the general conditions of stress equilibrium are:

$$
\begin{aligned}
& \frac{\partial \sigma_{x x}}{\partial x}+\frac{\partial \sigma_{x y}}{\partial y}+\frac{\partial \sigma_{x z}}{\partial z}=\mathrm{o}, \\
& \frac{\partial \sigma_{y y}}{\partial y}+\frac{\partial \sigma_{y x}}{\partial x}+\frac{\partial \sigma_{y z}}{\partial z}=\mathrm{o}, \\
& \frac{\partial \sigma_{z z}}{\partial z}+\frac{\partial \sigma_{z x}}{\partial x}+\frac{\partial \sigma_{z y}}{\partial y}=\rho g .
\end{aligned}
$$

In treating the case of an unconfined ice shelf we make the following assumptions:

(a) that the ice shelf is floating in hydrostatic equilibrium, so that

where $\rho_{\mathrm{w}}$ is the density of sea-water.

$$
(H-h) \rho_{\mathrm{w}}=H \rho,
$$

(b) that the ice shelf is free and uniform in the $y$-direction; no quantities vary in this direction, and shear stresses $\sigma_{x y}$ and $\sigma_{y z}$ are zero.

(c) that $\partial \sigma_{x z} / \partial x=0$. We shall see later (Equation ( $\left.\mathrm{I} 7\right)$ ) that this is strictly true if $\partial \theta / \partial x=0$.

The equilibrium Equations (4), (5), and (6) then reduce to

$$
\left.\begin{array}{rl}
\frac{\partial \sigma_{x x}}{\partial x}+\frac{\partial \sigma_{x z}}{\partial z} & =0, \\
\frac{\partial \sigma_{y y}}{\partial y} & =0, \\
\frac{\partial \sigma_{z z}}{\partial z} & =\rho g .
\end{array}\right\}
$$

Integrating Equation (9) we have, in general,

$$
\sigma_{z z}=\rho g z+\mathrm{f}(x, y),
$$

where $\mathrm{f}(x, y)$ is some arbitrary function of $x$ and $y$. At the upper surface, $z=h(x)$, vertical force balance requires that $\sigma_{z z}=\theta \sigma_{z x}$. However, we are for the moment assuming that $\sigma_{z x}$ is zero, therefore, since no quantities depend on $y$, and neglecting atmospheric pressure, we have $\sigma_{z z}=0$ at the upper surface. Then it follows that

$$
\sigma_{z z}=\rho g(z-h(x)) \text {. }
$$

Consider now the stress deviators. We have

$$
\sigma_{x x}^{\prime}=\sigma_{x x}-\frac{1}{3}\left(\sigma_{x x}+\sigma_{y y}+\sigma_{z z}\right),
$$

but since the ice shelf is unconfined in the $x$ and $y$ directions we must have

and hence

$$
\sigma_{x x}=\sigma_{y y},
$$

$$
\sigma_{x x}{ }^{\prime}=\sigma_{y y}{ }^{\prime}=\frac{1}{3}\left(\sigma_{x x}-\sigma_{z z}\right) .
$$

Also, assuming that ice is incompressible we have

$$
\dot{\epsilon}_{x x}+\dot{\epsilon}_{y y}+\dot{\epsilon}_{z z}=0,
$$


and, therefore, through the flow law (Equation (I))

$$
\sigma_{x x}{ }^{\prime}+\sigma_{y y}{ }^{\prime}+\sigma_{z z^{\prime}}=0 .
$$

Hence,

$$
\sigma_{z z}{ }^{\prime}=\frac{2}{3}\left(\sigma_{z z}-\sigma_{x x}\right) .
$$

In calculating $\tau^{2}$ in the flow law we shall treat the shear stress $\sigma_{x z}$ as small compared to the stress deviators. The result of our calculation will justify this assumption. By Equations (I I) and (12) this leads to

$$
\tau^{2}=\frac{1}{3}\left(\sigma_{x x}-\sigma_{z z}\right)^{2} .
$$

The equation for flow in the $x$-direction is then, from Equations ( $I$ ), ( $1 \mathrm{I}$ ), and ( 13 ),

$$
\dot{\epsilon}_{x x}=\frac{\mathrm{I}}{9}\left[\frac{\left(\sigma_{x x}-\sigma_{z z}\right)}{B}\right]^{3} \text {. }
$$

Inserting Equation (10) we then have

$$
\sigma_{x x}=B\left(9 \dot{\epsilon}_{x x}\right)^{\frac{1}{3}}+\rho g(z-h) .
$$

To achieve equilibrium of forces we must balance the total force of $\sigma_{x x}$ acting over a vertical column in the ice shelf with the total force of sea-water pressure acting on it. That is,

$$
\int_{-(H-h)}^{h} \sigma_{x x} \mathrm{~d} z=\int_{-(H-h)}^{\circ} \rho_{\mathrm{w}} g z \mathrm{~d} z .
$$

Performing these integrations using Equation (14) we find, assuming that $\dot{\epsilon}_{x x}$ is uniform with depth, that

$$
\dot{\epsilon}_{x x}=\frac{\mathrm{I}}{9}\left(\frac{\rho g h}{2 \bar{B}}\right)^{3}
$$

which we have simplified using Equation (7). $\bar{B}$ is the average of $B$ over depth. Substituting this into Equation (14) and now assuming $B$ uniform with depth, we have:

$$
\sigma_{x x}=\rho g(z-h / 2) .
$$

This gives $\sigma_{x x}$ as a function of depth for any thickness of ice shelf. The equation was achieved by overall balance of total internal force due to weight of ice with total external force due to sea-water pressure. We now ask whether stresses exactly balance each other at all depths through the ice shelf. We find that they do not, and that a vertical shear stress $\sigma_{x z}$ must be present to make up the balance.

Consider the equilibrium of a vertical column ABCDEFGH (Fig. 2). The sum of all forces on the six surfaces must be zero. We shall consider forces in the $x$-direction. There is zero traction on the surfaces ABFE, $A B C D$, and $\mathrm{EFGH}$, so if there is any imbalance between forces on AEHD and BFGC it must be counteracted by shear $\sigma_{z x}$ along CDHG. This is equivalent to integrating Equation (8) with respect to $z$. We have:

$$
\sigma_{z x} \delta x=\int_{z}^{h-\theta \delta x} \sigma_{x x}(x+\delta x) \mathrm{d} z-\int_{z}^{h} \sigma_{x x}(x) \mathrm{d} z .
$$

Performing these integrations using Equation (16) we find

$$
\sigma_{z x}(z)=-\rho g \theta z / 2 \text {. }
$$

This shows that on our simple model, in which density and flow parameter are constant with depth, shear stress varies linearly with depth, and is independent of flow parameter. It is zero at sea-level and maximum at the bottom of the ice shelf. 
By considering stresses on a small element near the surface, and using Equations (I0) and (I 7), it can be shown that the shear traction on the slanting upper and lower surfaces is indeed zero, as it should be. Vertical forces at the surfaces do not balance properly, since we earlier assumed that $\sigma_{z z}=0$ at the upper surface, and yet we have now shown the existence of a non-zero shear stress $\sigma_{z x}=-\rho g \theta h / 2$. Since $\sigma_{z z}=\theta \sigma_{z x}$ we should strictly now have $\sigma_{z z}=-\frac{1}{2} \rho g h \theta^{2}$. The analysis thus contains a slight discrepancy. The error is a second-order correction and could be included if the whole procedure were to be iterated further.

From Equations (I I) and (I6) we find that

$$
\sigma_{x x^{\prime}}=\rho g h / 6 .
$$

Therefore,

$$
\sigma_{z x}=-3^{\theta} \theta(z / h) \sigma_{x x}{ }^{\prime} .
$$

Surface slopes of unconfined ice shelves are generally small. For Erebus Glacier tongue (Holdsworth, 1974), $\theta$ is approximately $3 \times 10^{-3}$. Since $z$ can be at most some six times the magnitude of $h$ we see that $\sigma_{z x}$ is at most five per cent of the magnitude of $\sigma_{x x}{ }^{\prime} . \sigma_{z x}$ is therefore generally negligible in comparison with $\sigma_{x x}{ }^{\prime}$, especially since we generally find ourselves comparing the squares of these quantities, as in Equation (3).

We can also perform the calculation for a real case in which density and temperature vary with depth. The calculation is lengthy and does not lead to a simple analytic answer like that of Equation ( 17 ), but it follows the same principles as above. For a particular case we look at Erebus Glacier tongue and use data from Holdsworth (1974). We assume that density varies with depth according to the model of Schytt (I958) and we adopt a temperature variation similar to those in Wexler (1960). We assume that the flow parameter $B$ has a Boltzmann temperature dependence (Paterson, i969, p. 83)

$$
B^{-3}=A \exp (-Q / R T) \text {, }
$$

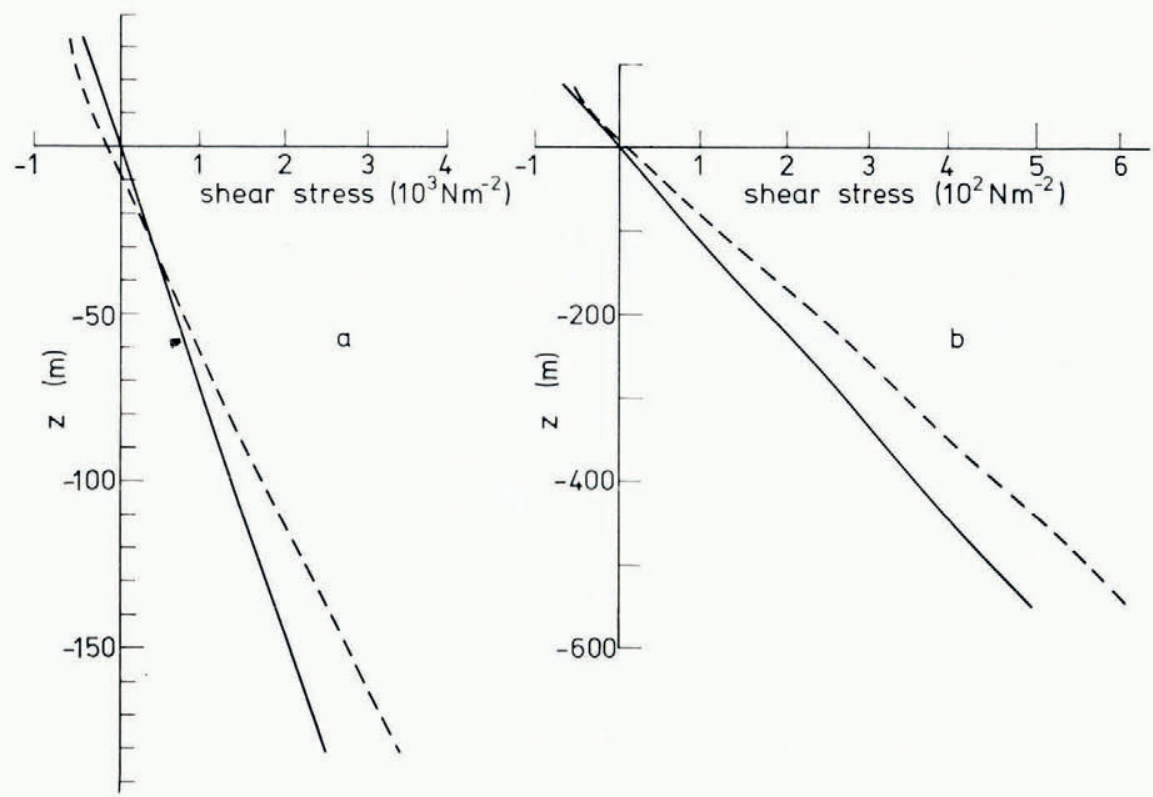

Fig. 3. Shear stress as a function of height $z$ above sea-level for (a) Erebus Glacier Tongue (unconfined); (b) Amery Ice Shel, (confined). The solid line shows the result of assuming density and temperature constant with depth, and the dashed line shows the result of allowing them to vary realistically. 
where

$$
Q / R=7.293 \times 10^{3} \mathrm{~K},
$$

and $T$ is the absolute temperature.

We fit the constant $A$ in order to agree with value of $\bar{B}$ found by Holdsworth from his data. The result of the calculation, carried out for a point five kilometres from the hinge zone, is shown in Figure 3 a. It is shown together with the result obtained by assuming a constant density and flow parameter, as in Equation (17). The shear stresses in the two cases are significantly different, but show the same form and order of magnitude.

\section{Confined bay ice shelves}

Consider now an ice shelf in a parallel-sided bay (Thomas, I973[b], fig. 2). The ice shelf is confined in the $y$-direction and undergoes shear at the sides. We assume that shear stress at the sides reaches a limiting value $\tilde{\tau}_{\mathrm{s}}$ (Thomas, 1973[b]) and write

and, therefore,

$$
\sigma_{x y}=y \frac{\partial \sigma_{x y}}{\partial y}
$$

$$
\frac{\partial \sigma_{x y}}{\partial y}=\frac{\bar{\tau}_{\mathrm{s}}}{\lambda}
$$

where $\lambda$ is the half-width of the ice shelf. We still assume that $\partial \sigma_{x y} / \partial x=0$, since $\bar{\tau}_{\mathrm{s}}$ and $\lambda$ are independent of $x$, and that $\partial \sigma_{z x} / \partial x=0$. We assume that $\sigma_{z y}=0$. We can then write Equations (4), (5), and (6) as

$$
\begin{aligned}
\frac{\partial \sigma_{x x}}{\partial x}+\frac{\partial \sigma_{x z}}{\partial z}+\frac{\bar{\tau}_{\mathrm{s}}}{\lambda} & =0, \\
\frac{\partial \sigma_{y y}}{\partial y} & =0, \\
\frac{\partial \sigma_{z z}}{\partial z} & =\rho g
\end{aligned}
$$

Now $\dot{\epsilon}_{y y}=\mathrm{o}$ and therefore $\sigma_{y y}{ }^{\prime}=\mathrm{o}$ by Equation (I) so that we have from Equation (2)

$$
\sigma_{x x}=2 \sigma_{x x}{ }^{\prime}+\sigma_{z z} \text {. }
$$

We continue to treat shear stresses as small in the effective stress expression Equation (3) and we find this leads to

$$
\tau^{2}=\frac{1}{4}\left(\sigma_{x x}-\sigma_{z z}\right)^{2} .
$$

Therefore, by Equations (I), (19), and (20)

$$
\dot{\epsilon}_{x x}=\frac{\mathrm{I}}{8}\left(\frac{\sigma_{x x}-\sigma_{z z}}{B}\right)^{3} .
$$

From Equation (18) we still have

and so

$$
\sigma_{z z}=\rho g(z-h(x))
$$

$$
\sigma_{x x}=2 B \dot{\boldsymbol{\epsilon}}_{x x^{3}}+\rho g(z-h(x)) .
$$

Creep in a bay ice shelf is given by (Thomas, $1973[\mathrm{~b}]$ )

$$
\dot{\boldsymbol{\epsilon}}_{x x}(x)=\left[\frac{\rho g h}{{ }_{4} \bar{B}}+\frac{\bar{\tau}_{\mathrm{s}}}{{ }_{2} \bar{B} H} \int_{x}^{X} \frac{H}{\lambda} d x\right]^{3},
$$


where $x=X$ marks the seaward margin of the ice shelf. By considering the dependence of this function on $x$ we find that to first order in small quantities $\delta x$ we can write

$$
\dot{\epsilon}_{x x}(x+\delta x)=\left[\frac{\rho g}{{ }_{4} \bar{B}}(h-\theta \delta x)+\left(\mathrm{I}+\frac{\theta \delta x}{h}\right) \frac{\bar{\tau}_{\mathrm{s}}}{{ }_{2} \bar{B} H} \int_{x}^{X} \frac{H}{\lambda} d x-\frac{\bar{\tau}_{\mathrm{s}}}{{ }_{2} \bar{B} \lambda} \cdot \delta x\right]^{3} .
$$

We can now, as before, consider the balance of stresses on a column in the ice shelf. Consider the column ABCDEFGH (Fig. 2). We must equate the forces in the $x$-direction over all the surfaces of the volume, but we now have to include horizontal shear stress on the surfaces $\mathrm{ABCD}$ and EFGH. The force due to stresses on these surfaces is simply

$$
\left(\bar{\tau}_{\mathrm{s}} / \lambda\right)(h-z) \delta x \delta y,
$$

so we can write

$$
\sigma_{z x} \delta x \delta y=\frac{\bar{\tau}_{\mathrm{S}}}{\lambda}(h-z) \delta x \delta y+\delta y \int_{z}^{h-\theta \delta x} \sigma_{x x}(x+\delta x) \mathrm{d} z-\delta y \int_{z}^{h} \sigma_{x x}(x) \mathrm{d} z .
$$

We perform these integrations using Equations (2I), (22), and (23) and we find that

$$
\sigma_{z x}=-\frac{\theta z}{h}\left(\frac{\rho g h}{2}+\frac{\bar{\tau}_{\mathrm{s}}}{H} \int_{x}^{x} \frac{H}{\lambda} \mathrm{d} x\right) .
$$

Again, we find that the simple model with a constant density and flow parameter leads to a shear stress which is linearly dependent on depth and zero at sea-level. The two terms in Equation (24) are of different sign, since $\bar{\tau}_{s}$ is negative; the shear stress may therefore have different senses, depending on which term dominates. In practice the term $\rho g h / 2$ is generally the greater, which corresponds to the state of extending flow generally found in ice shelves.

From Equations (I9), (2 I), and (22) we find that the horizontal stress deviator is given by

$$
\sigma_{x x^{\prime}}=\frac{\mathrm{I}}{2}\left(\frac{\rho g h}{2}+\frac{\bar{\tau}_{\mathrm{s}}}{H} \int_{x}^{x} \frac{H}{\lambda} \mathrm{d} x\right)
$$

and therefore

$$
\sigma_{z x}=-\frac{2 \theta z}{h} \sigma_{x x}
$$

Looking at data for the Amery Ice Shelf (Thomas, 1973[a]) we see that surface slopes are about $3 \times 10^{-4}$. This means that shear stresses are at most some $0.4{ }^{\circ}$ of direct stress deviators. It is therefore again true to say that they are negligible.

As for the unconfined ice shelf treated above we can also carry out the calculation using realistic assumptions about density and temperature profiles. Using data for station G2 on the Amery Ice Shelf we find again that shear stress is essentially of the same form and magnitude as that calculated on the simple model. Figure $3^{b}$ shows shear stress as a function of depth for the two models.

\section{Shear strain-rates}

We consider now the deformation produced by the calculated shear stresses. We write the flow law as

$$
\dot{\epsilon}_{z x}=\frac{\tau^{2}}{B^{3}} \sigma_{z x}
$$


and allow $B$ to vary with depth in a realistic manner. For an unconfined ice shelf it is readily shown that

$$
\tau^{2}=3^{-\frac{1}{3}} B^{2} \dot{\epsilon} x x^{\frac{2}{3}},
$$

where $\dot{\epsilon}_{x x}$ is given by Equation (15). For a confined ice shelf we can show similarly that

$$
\tau^{2}=B^{2} \dot{\epsilon} x x^{\frac{2}{3}} \text {, }
$$

where $\dot{\epsilon}_{x x}$ is given by Equation (22). Strain-rates can then be found using these relations and the same temperature and flow law assumptions as in Section I.

Such shear strain-rates lead to differential motion between the top and bottom of the ice shelf. For pure shear we have

$$
\dot{\epsilon}_{z x}=\partial u_{x} / \partial z
$$

where $u_{x}$ is the $x$ component of velocity, so that

$$
u_{x}(s)-u_{x}(b)=\int_{b}^{s} \dot{\epsilon}_{z x} \mathrm{~d} z,
$$

where $s$ and $b$ denote the upper and lower surfaces of the ice shelf. Integrating numerically we find that the differential motion between the top and bottom of the shelf is $18 \mathrm{~mm} \mathrm{a}^{-1}$ for the Erebus Glacier tongue and $25 \mathrm{~mm} \mathrm{a}^{-1}$ for the Amery Ice Shelf; the top is moving faster than the bottom. These movements are negligible, perhaps not even detectable.

MS. received 25 May $197^{8}$ and in revised form 26 October 1978

\section{REFERENCES}

Budd, W. F. 1966. The dynamics of the Amery Ice Shelf. Fournal of Glaciology, Vol. 5, No. 45, p. 335-58.

Holdsworth, G. 1974. Erebus Glacier tongue, McMurdo Sound, Antarctica. Journal of Glaciology, Vol. I3, No. 67 , p. $27-35$.

Paterson, W. S. B. I969. The physics of glaciers. Oxford, etc., Pergamon Press. (The Commonwealth and International Library. Geophysics Division.)

Robin, G. de Q. 1953. Measurements of ice thickness in Dronning Maud Land, Antarctica. Nature, Vol. 171, No. 434 I, p. 55-58.

Robin, G. de Q. 1975. Ice shelves and ice flow. Nature, Vol. 253, No. 5488, p. 168-72.

Sanderson, T. J. O. In press. Equilibrium profile of ice shelves. Fournal of Glaciology, Vol. 22, No. 88.

Schytt, V. I 958 . Glaciology. II. The inner structure of the ice shelf at Maudheim as shown by core drilling. Norwegian-British-Szedish Antarctic Expedition, 1949-1952. Scientific Results, Vol. 4, C.

Thomas, R. H. 1973[a]. The creep of ice shelves: interpretation of observed behaviour. Fournal of Glaciology, Vol. 12, No. 64, p. 55-70.

Thomas, R. H. 1973[b]. The creep of ice shelves: theory. Fournal of Glaciology, Vol. 12, No. 64, p. 45-53.

Weertman, J. 1957. Deformation of floating ice shelves. Fournal of Glaciology, Vol. 3, No. 21, p. 38-42.

Wexler, H. 1960. Heating and melting of floating ice shelves. Fournal of Glaciology, Vol. 3, No. 27, p. 626-45. 